\title{
Alcoholic Dementia in the Context of an Entropy of Neuron- Glial Network of a Brain
}

\author{
Volkov VP* \\ Physician of Functional Diagnostics of SBIH, Regional Psychoneurological Clinic, Russia
}

Submission: November 22, 2017; Published: December 06, 2017

*Corresponding author: Rosman SV, Physician of Functional Diagnostics of SBIH, Regional Psychoneurological Clinic, Russian Federation, Russia, Tel: +7-903-800-11-05; Email: seros2005@mail.ru

\begin{abstract}
In article an attempt of systematization of the neurophysiological changes observed at an alcoholic dementia in comparison with dementias of other genesis by means of a new technique - dispersion of amplitude-frequency characteristics of an alpha rhythm - for the purpose of identification of the common regularities of development of psychopathology, creation of naturally-scientific systematization of mental diseases on a basis the dimensional of neurophysiological methods is made.

Keywords: Alcohol Dimension; Entropy of the Neuron - Glial Network of the Brain; Dispersion of Alpha - Rhythm; Diagnosis of Mental Illness

Abbreviations: AD: Alcohol dimension (F10.73 ICD-10); DD: Dementia in Other Specified Diseases Classified Elsewhere (F02.8x ICD-10); VD: Vascular dementia (F01.x ICD-10); DAFCAR: Dispersion of Amplitude - Frequency Characteristics of the Alpha Rhythm EEG; NGNB: Neuron - Glial Network of the Brain; HVT: Hyperventilation Test; CD $\alpha$ : Coefficient of Dispersion of Alpha - Rhythm EEG-1(the quotient of the modal values of power of alpha rhythm to his total power in the range of 7-13 Hz); CD 2: Coefficient of Dispersion of the alpha - Rhythm EEG-2(the quotient of the power of the alpha rhythm in the range of "a modal value $\pm 0.5 \mathrm{~Hz}$ " to his total power in the range of 7-13 Hz); $0 \mathrm{Mo} f$ : Value of the Modal Frequencies in Occipital Electrodes; F Mo f: Value of the Modal Frequencies in Frontal Electrodes; O Mo f - F Mo f: Value of the Difference of Modal Frequencies Between the Occipital and Frontal Electrodes; IIDA: Integral Index of Dispersion of the Alpha rhythm EEG (Value of the Kurtosis of the Normal Distribution CDol in the Occipital Electrodes); ADA: Asymmetry Distribution of the Alpha rhythm EEG (Value of the Asymmetry Distribution $\mathrm{CD \alpha l}$ in the Occipital Electrodes); IIH: Value of the Index Hypofrontality (Kurtosis of the Normal Distribution CD $\alpha$ in the Frontal Electrodes); AH: Value of the Asymmetry of CD $\alpha$ l in the Frontal Electrodes; CV\%: The Coefficient of Variation; CI: Confidence Interval; CU: conditional Unit
\end{abstract}

\section{Introduction}

According to data of epidemiological researches, the incidence in population of an alcoholism among the full age population is up to $10 \%$. It has a special medico-social significance in connection with steady body height of these indexes with distribution on a teenage age. It is difficult to estimate social consequences of development of the neuropsychological violations arising at the same time. Will not be larger exaggeration to assume that decrease in level of violent crime in lack of an alcoholism would make not less than $70 \%$. One of the leading symptoms of alcoholic damage of a brain is the progressing violation of intellectual functions against the background of the expressed deviant behavior $[1,2]$. According to various authors these violations come to light in $50-70 \%$ of cases and in $10 \%$ of cases they have the expressed character reaching degree of a dementia [3-5]. At the same time it is considered that a dementia, the bound to alcoholism, makes up to $10 \%$ of all cases of a dementia, especially at persons of a young age.

\section{Research objective}

Searching of regularities in changes of the verified neurophysiological markers at an alcoholic dementia and dementias of other genesis on the basis of measurement of level of entropy of NGNB by means of the DAFCAR indexes.

\section{Materials and Methods}

The reference technique of realization of an EEG with an arrangement of electrodes on the international system "10$20 \%$ " and ipsilateral ear electrodes was carried out. Test from a hyperventilation was carried out by a reference technique with dispersion assessment of changes of an alpha rhythm by S.V. Rosman's method 2017. The DAFCAR parameters were calculated by S.V. Rosman's method 2013 by means of the Microsoft Excel and Statistica 10.0 programs [6]. For researches young people, middle age and elderly patients for minimization of influence of age changes of involution character are selected. All patients the research was carried out during performing therapy by psychotropic and sedative 


\section{Global Journal of Addiction \& Rehabilitation Medicine}

drugs. For comparison patients with dementias of various genesis and control group (the patients recognized as experts

Table 1: Distribution of patients in a comparative experiment of research DAFCAR among some types of psychopathology.

\begin{tabular}{|c|c|c|c|c|}
\hline \multirow{3}{*}{ Diseases } & \multicolumn{4}{|c|}{ Gender } \\
\hline & \multicolumn{2}{|c|}{ Men } & \multicolumn{2}{|c|}{ Women } \\
\hline & Age (year) CI & Quantity researches & Age (year) CI & Quantity researches \\
\hline \multirow{2}{*}{$\mathrm{AD}$} & 43 & \multirow{2}{*}{376} & 44 & \multirow{2}{*}{73} \\
\hline & $42-44$ & & $40-47$ & \\
\hline \multirow{2}{*}{ DD } & 48 & \multirow{2}{*}{344} & 48 & \multirow{2}{*}{148} \\
\hline & $46-49$ & & $45-50$ & \\
\hline \multirow{2}{*}{ VD } & 68 & \multirow{2}{*}{78} & 68 & \multirow{2}{*}{70} \\
\hline & $64-72$ & & $64-72$ & \\
\hline \multirow{2}{*}{ Health } & 21 & \multirow{2}{*}{61} & 34 & \multirow{2}{*}{13} \\
\hline & $20-22$ & & $26-41$ & \\
\hline
\end{tabular}

Results

\section{Discussion of Results}

First of all, it should be noted some features of the studied pathological processes:

a) It is impossible to claim with the complete accuracy and reliability that among patients of one group there are no patients of other group - it is possible to divide them only with a particular share of convention.

b) The DAFCAR some indexes at it is long the proceeding processes have rather wide spacing of mean values in selection depending on weight of course of process. At the same time it does not reduce the diagnostic value of their calculation in dynamics at each specific patient. At the same time the studied statistics reveal regularities and correlate among themselves and clinic of diseases.

As in all previous articles of a cycle [7-14], assessment of dispersion changes begins with studying of cartograms (Figures 1-6). The common feature of all cartograms is the considerable common shift of moral values - up to $8.5 \mathrm{~Hz}$ less. At AD there is a shift of schedules to the left in frontal assignments (Fp1, Fp2, F3, F4, F7, F8) rather occipital (01, 02). As it was specified in articles about schizophrenia, this sign is a hypofrontality marker, and, the more the size of this shift, the disease proceeds more sharply. At values of this difference more than $1 \mathrm{HZ}$ at patient's hallucinations and nonsense are observed. At AD this difference less than $0.75 \mathrm{~Hz}$, i.e. is less, than at schizophrenia.
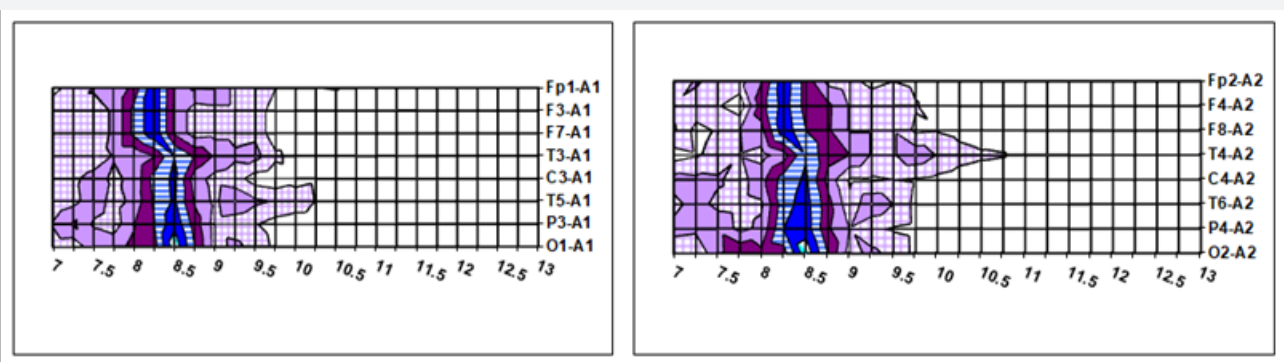

Figure 1: Average dispersion cartogram of an alpha rhythm at the alcoholic dementia (AD), men. Hereinafter at the left - the left-hand hemisphere, on the right - the right hemisphere; on a horizontal axis - the frequency of an alpha rhythm, $\mathrm{Hz}$, on a vertical axis - assignments of an EEG.
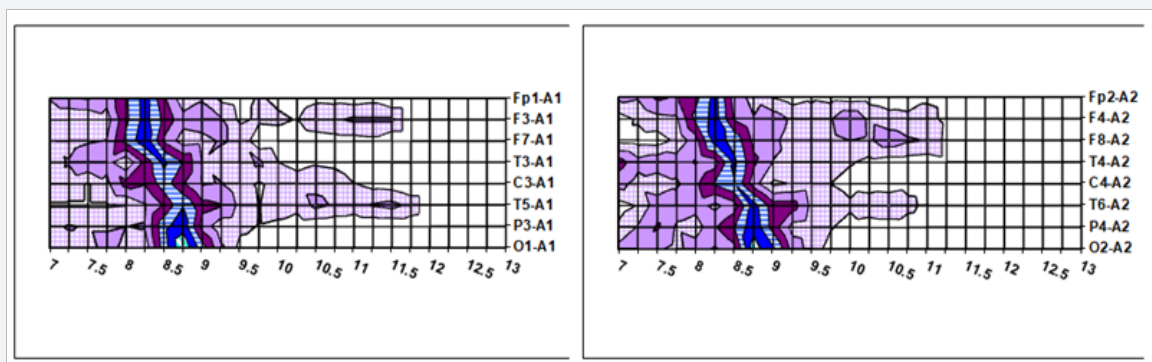

Figure 2: Average Dispersion Cartogram of Alpha Rhythm at AD, women. 

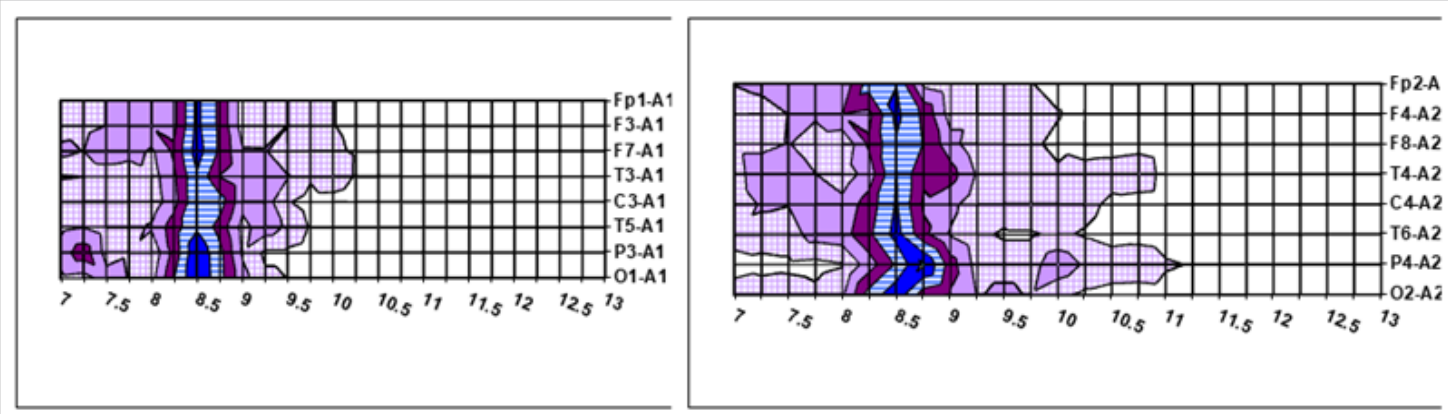

Figure 3: Average Dispersion Cartogram of Alpha Rhythm at a dementia at other diseases (DD), men.

Table 2: Comparative statistical data on indexes of DAFCAR at the examined contingent, Left hemisphere.

\begin{tabular}{|c|c|c|c|c|c|c|c|c|c|}
\hline \multirow{2}{*}{ Gender } & \multirow{2}{*}{ Index DAFCAR } & \multirow{2}{*}{ Health } & \multirow{2}{*}{ AD } & \multirow{2}{*}{ DD } & \multirow{2}{*}{ VD } & \multicolumn{4}{|c|}{ CV \% } \\
\hline & & & & & & Health & AD & DD & VD \\
\hline \multirow{26}{*}{ Men } & \multirow{2}{*}{ O Mo f } & 10.26 & 8.22 & 8.62 & 7.97 & 6 & 9 & 14 & 10 \\
\hline & & $10.11-10.4$ & 8.14-8.29 & 8.49-8.75 & 7.74-8.19 & & & & \\
\hline & \multirow{2}{*}{ O Mo f - F Mo F } & 0.04 & 0.49 & 0.28 & 0.28 & 242 & 201 & 98 & 96 \\
\hline & & 0.01-0.06 & $0.39-0.58$ & $0.25-0.31$ & $0.2-0.36$ & & & & \\
\hline & \multirow{2}{*}{$\mathrm{CD} \alpha 1$} & 0.288 & 0.167 & 0.156 & 0.159 & 13 & 43 & 45 & 46 \\
\hline & & $0.278-0.297$ & $0.16-0.174$ & $0.148-0.163$ & $0.138-0.181$ & & & & \\
\hline & \multirow{2}{*}{$\mathrm{CD} \alpha 2$} & 0.748 & 0.48 & 0.468 & 0.443 & 9 & 36 & 44 & 35 \\
\hline & & $0.731-0.765$ & $0.462-0.498$ & $0.446-0.49$ & $0.399-0.488$ & & & & \\
\hline & \multirow{2}{*}{ IIDA } & 7.142 & 3.075 & 2.474 & 2.27 & 27 & 107 & 131 & 159 \\
\hline & & $6.657-7.627$ & 2.741-3.408 & $2.129-2.818$ & $1.219-3.321$ & & & & \\
\hline & \multirow{2}{*}{ ADA } & 2.704 & 1.724 & 1.532 & 1.511 & 11 & 44 & 52 & 53 \\
\hline & & $2.63-2.778$ & $1.647-1.801$ & $1.448-1.616$ & $1.279-1.743$ & & & & \\
\hline & \multirow{2}{*}{ IIH } & 6.735 & 2.534 & 2.081 & 1.86 & 33 & 126 & 144 & 140 \\
\hline & & 6.164-7.305 & $2.21-2.858$ & $1.763-2.398$ & $1.103-2.618$ & & & & \\
\hline & \multirow{2}{*}{$\mathrm{AH}$} & 2.58 & 1.518 & 1.403 & 1.374 & 15 & 53 & 54 & 51 \\
\hline & & 2.481-2.679 & $1.437-1.599$ & $1.323-1.484$ & $1.17-1.579$ & & & & \\
\hline & \multirow{2}{*}{ Alfa-1/Alfa } & 0.13 & 0.518 & 0.501 & 0.567 & 35 & 31 & 37 & 26 \\
\hline & & $0.118-0.142$ & $0.502-0.534$ & $0.481-0.521$ & $0.525-0.61$ & & & & \\
\hline & \multirow{2}{*}{ Alfa-2/Alfa } & 0.772 & 0.358 & 0.374 & 0.326 & 18 & 39 & 42 & 36 \\
\hline & & $0.736-0.807$ & $0.344-0.372$ & $0.357-0.391$ & $0.292-0.36$ & & & & \\
\hline & \multirow{2}{*}{ Alfa-3/Alfa } & 0.134 & 0.145 & 0.147 & 0.124 & 128 & 53 & 60 & 51 \\
\hline & & $0.09-0.178$ & $0.137-0.153$ & $0.138-0.157$ & $0.106-0.143$ & & & & \\
\hline & \multirow{2}{*}{ IZ } & 0.138 & 0.075 & 0.078 & 0.035 & 82 & 174 & 171 & 344 \\
\hline & & $0.109-0.166$ & $0.062-0.089$ & 0.064-0.092 & $0-0.069$ & & & & \\
\hline & \multirow{2}{*}{ Age } & 21.492 & 43.42 & 48.015 & 68.833 & 27 & 32 & 32 & 20 \\
\hline & & $20-22$ & $42-44$ & $46-49$ & $64-72$ & & & & \\
\hline & \multirow{2}{*}{ O Mo f } & 10.17 & 8.22 & 8.56 & 8.06 & 6 & 9 & 14 & 9 \\
\hline & & $9.82-10.52$ & 8.04-8.39 & 8.36-8.76 & 7.88-8.25 & & & & \\
\hline & \multirow{2}{*}{ O Mo f - F Mo F } & 0.12 & 0.53 & 0.3 & 0.36 & 143 & 130 & 110 & 92 \\
\hline & & $0.02-0.22$ & $0.37-0.7$ & $0.25-0.36$ & $0.28-0.44$ & & & & \\
\hline & \multirow{2}{*}{$\mathrm{CD} \alpha 1$} & 0.279 & 0.17 & 0.151 & 0.144 & 21 & 45 & 43 & 34 \\
\hline & & $0.243-0.314$ & $0.152-0.189$ & $0.14-0.161$ & $0.132-0.155$ & & & & \\
\hline & \multirow{2}{*}{$\mathrm{CD} \alpha 2$} & 0.759 & 0.476 & 0.44 & 0.438 & 10 & 34 & 36 & 31 \\
\hline & & $0.715-0.803$ & $0.437-0.514$ & $0.414-0.466$ & $0.405-0.47$ & & & & \\
\hline
\end{tabular}


Global Journal of Addiction \& Rehabilitation Medicine

\begin{tabular}{|c|c|c|c|c|c|c|c|c|c|}
\hline \multirow{18}{*}{ Women } & \multirow{2}{*}{ IIDA } & 6.23 & 3.446 & 2.18 & 1.578 & 38 & 113 & 148 & 172 \\
\hline & & $4.786-7.673$ & $2.539-4.352$ & $1.655-2.706$ & $0.93-2.226$ & & & & \\
\hline & \multirow{2}{*}{$\mathrm{ADA}$} & 2.578 & 1.78 & 1.483 & 1.36 & 17 & 47 & 52 & 50 \\
\hline & & $2.317-2.838$ & $1.585-1.975$ & $1.357-1.608$ & $1.198-1.522$ & & & & \\
\hline & \multirow{2}{*}{ IIH } & 5.381 & 2.496 & 1.526 & 1.588 & 29 & 121 & 162 & 167 \\
\hline & & $4.433-6.329$ & $1.794-3.199$ & $1.124-1.928$ & $0.955-2.222$ & & & & \\
\hline & \multirow{2}{*}{$\mathrm{AH}$} & 2.365 & 1.524 & 1.268 & 1.303 & 13 & 49 & 56 & 53 \\
\hline & & $2.173-2.557$ & $1.351-1.698$ & $1.154-1.383$ & $1.138-1.467$ & & & & \\
\hline & \multirow{2}{*}{ Alfa-1/Alfa } & 0.118 & 0.502 & 0.485 & 0.562 & 38 & 30 & 39 & 22 \\
\hline & & 0.091-0.145 & $0.467-0.538$ & $0.455-0.515$ & $0.532-0.592$ & & & & \\
\hline & \multirow{2}{*}{ Alfa-2/Alfa } & 0.802 & 0.378 & 0.391 & 0.335 & 10 & 38 & 40 & 33 \\
\hline & & $0.751-0.852$ & $0.345-0.412$ & $0.366-0.417$ & $0.309-0.362$ & & & & \\
\hline & \multirow{2}{*}{ Alfa-3/Alfa } & 0.114 & 0.14 & 0.145 & 0.12 & 98 & 55 & 66 & 48 \\
\hline & & $0.046-0.182$ & $0.122-0.158$ & $0.129-0.161$ & $0.106-0.134$ & & & & \\
\hline & \multirow{2}{*}{ IZ } & 0.16 & 0.067 & 0.08 & 0.052 & 69 & 212 & 162 & 209 \\
\hline & & $0.094-0.227$ & $0.034-0.101$ & 0.059-0.101 & $0.026-0.078$ & & & & \\
\hline & \multirow{2}{*}{ Age } & 34.1 & 43.9 & 48.4 & 68.4 & 36 & 30 & 31 & 23 \\
\hline & & $26.6-41.5$ & $40.8-47.0$ & $45.9-50.9$ & $64.6-72.2$ & & & & \\
\hline
\end{tabular}

Note: numerator - mean value, a denominator $-\mathrm{Cl} \pm 95 \%$

Table 3: Comparative statistical data on indexes of DAFCAR at the examined contingent. Right hemisphere.

\begin{tabular}{|c|c|c|c|c|c|c|c|c|c|}
\hline \multirow{2}{*}{ Gender } & \multirow{2}{*}{ Index DAFCAR } & \multirow{2}{*}{ Health } & \multirow{2}{*}{ AD } & \multirow{2}{*}{ DD } & \multirow{2}{*}{ VD } & \multicolumn{4}{|c|}{ CV \% } \\
\hline & & & & & & Health & AD & DD & VD \\
\hline \multirow{24}{*}{ Men } & \multirow{2}{*}{ O Mo f } & 10.25 & 8.39 & 8.64 & 8.07 & 5 & 11 & 14 & 11 \\
\hline & & 10.1-10.39 & $8.29-8.48$ & $8.5-8.77$ & 7.82-8.32 & & & & \\
\hline & \multirow{2}{*}{ O Mo f - F Mo F } & 0.04 & 0.62 & 0.27 & 0.23 & 228 & 163 & 113 & 109 \\
\hline & & $0.02-0.06$ & $0.52-0.72$ & $0.24-0.3$ & $0.16-0.31$ & & & & \\
\hline & \multirow{2}{*}{$\mathrm{CD} \alpha 1$} & 0.298 & 0.166 & 0.159 & 0.163 & 14 & 42 & 47 & 38 \\
\hline & & $0.287-0.308$ & $0.158-0.173$ & $0.151-0.167$ & $0.144-0.181$ & & & & \\
\hline & \multirow{2}{*}{$\mathrm{CD} \alpha 2$} & 0.767 & 0.474 & 0.464 & 0.472 & 9 & 34 & 39 & 37 \\
\hline & & $0.75-0.784$ & $0.458-0.49$ & $0.445-0.484$ & $0.422-0.522$ & & & & \\
\hline & \multirow{2}{*}{ IIDA } & 7.325 & 3.059 & 2.588 & 2.778 & 27 & 107 & 129 & 121 \\
\hline & & $6.814-7.835$ & $2.728-3.39$ & $2.235-2.941$ & $1.802-3.754$ & & & & \\
\hline & \multirow{2}{*}{ ADA } & 2.738 & 1.701 & 1.563 & 1.707 & 11 & 46 & 52 & 42 \\
\hline & & $2.662-2.814$ & $1.622-1.78$ & $1.477-1.648$ & $1.5-1.914$ & & & & \\
\hline & \multirow{2}{*}{$\mathrm{IIH}$} & 6.395 & 2.469 & 2.113 & 1.762 & 37 & 137 & 137 & 142 \\
\hline & & 5.784-7.005 & $2.126-2.813$ & $1.806-2.421$ & $1.037-2.488$ & & & & \\
\hline & \multirow{2}{*}{$\mathrm{AH}$} & 2.517 & 1.482 & 1.402 & 1.362 & 18 & 58 & 54 & 50 \\
\hline & & $2.404-2.631$ & $1.395-1.569$ & $1.321-1.483$ & $1.166-1.559$ & & & & \\
\hline & \multirow{2}{*}{ Alfa-1/Alfa } & 0.113 & 0.517 & 0.498 & 0.537 & 38 & 32 & 39 & 29 \\
\hline & & $0.102-0.125$ & $0.5-0.533$ & $0.477-0.518$ & $0.492-0.583$ & & & & \\
\hline & \multirow{2}{*}{ Alfa-2/Alfa } & 0.792 & 0.361 & 0.378 & 0.348 & 18 & 40 & 44 & 39 \\
\hline & & $0.756-0.829$ & $0.346-0.375$ & $0.361-0.396$ & $0.308-0.387$ & & & & \\
\hline & \multirow{2}{*}{ Alfa-3/Alfa } & 0.094 & 0.123 & 0.124 & 0.115 & 157 & 58 & 66 & 53 \\
\hline & & $0.056-0.132$ & $0.116-0.13$ & $0.116-0.133$ & $0.097-0.133$ & & & & \\
\hline & \multirow{2}{*}{ IZ } & 0.24 & 0.106 & 0.112 & 0.084 & 37 & 123 & 125 & 151 \\
\hline & & $0.217-0.263$ & $0.093-0.119$ & $0.097-0.126$ & $0.047-0.121$ & & & & \\
\hline
\end{tabular}


Global Journal of Addiction \& Rehabilitation Medicine

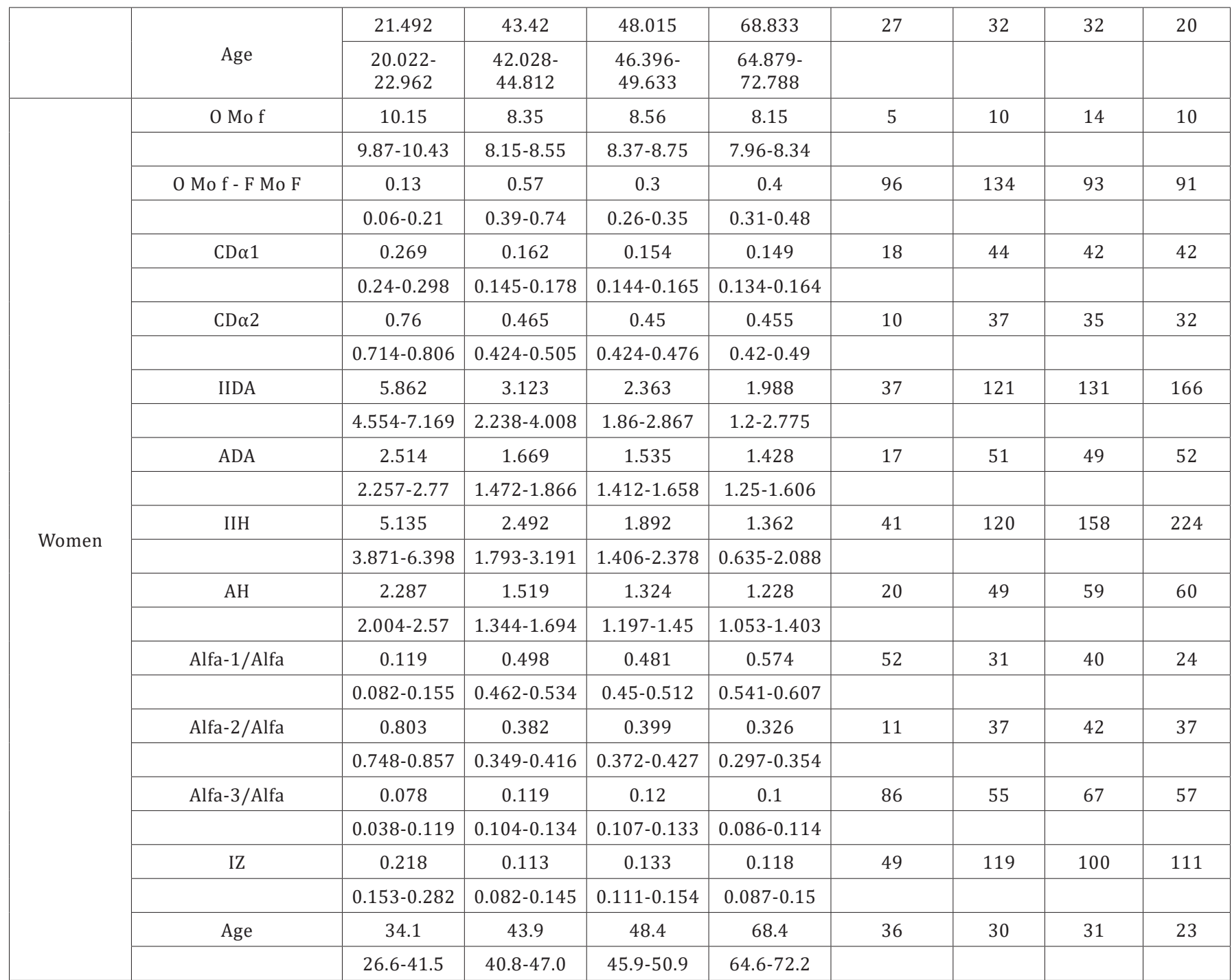

Note: numerator - mean value, a denominator $-\mathrm{Cl} \pm 95 \%$

Table 4: Statistical reliability of differences between mean values of indexes of dispersion of DAFCAR in groups of patients with a dementia on Student-test (t-value).

\begin{tabular}{|c|c|c|c|c|c|c|c|}
\hline $\begin{array}{l}\text { Indexes } \\
\text { DAFCAR }\end{array}$ & Gender & Hemisphere & Mean AD & Mean VD & t-value & df & $\mathbf{p}$ \\
\hline $\mathrm{AH}$ & women & right & 1.519 & 1.228 & 2.351 & 141.000 & 0.020 \\
\hline $\mathrm{ADA}$ & women & left & 1.780 & 1.360 & 3.294 & 141.000 & 0.001 \\
\hline Alpha-1/ Alpha & women & левое & 0.502 & 0.562 & -2.567 & 141.000 & 0.011 \\
\hline Alpha-1/ Alpha & women & right & 0.498 & 0.574 & -3.084 & 141.000 & 0.002 \\
\hline IIH & women & right & 2.492 & 1.362 & 2.236 & 141.000 & 0.027 \\
\hline IIDA & women & left & 3.446 & 1.578 & 3.318 & 141.000 & 0.001 \\
\hline $\mathrm{CD} \alpha 1$ & women & left & 0.170 & 0.144 & 2.478 & 141.000 & 0.014 \\
\hline $\mathrm{IZ}$ & men & left & 0.075 & 0.035 & 2.044 & 422.000 & 0.042 \\
\hline O Mo f & men & left & 8.217 & 7.969 & 2.240 & 422.000 & 0.026 \\
\hline O Mo f & men & right & 8.386 & 8.073 & 2.186 & 422.000 & 0.029 \\
\hline O Mo f - F Mo F & men & right & 0.618 & 0.234 & 2.626 & 422.000 & 0.009 \\
\hline \multirow[t]{2}{*}{ Alpha-1/ Alpha } & men & left & 0.518 & 0.567 & -2.069 & 422.000 & 0.039 \\
\hline & Gender & Hemisphere & Mean AD & Mean DD & t-value & $\mathrm{df}$ & $\mathrm{p}$ \\
\hline$C D \alpha 1$ & women & left & 0.170 & 0.151 & 2.016 & 219.000 & 0.045 \\
\hline
\end{tabular}




\section{Global Journal of Addiction \& Rehabilitation Medicine}

\begin{tabular}{|c|c|c|c|c|c|c|c|}
\hline IIDA & women & left & 3.446 & 2.180 & 2.555 & 219.000 & 0.011 \\
\hline $\mathrm{ADA}$ & women & left & 1.780 & 1.483 & 2.626 & 219.000 & 0.009 \\
\hline IIH & women & left & 2.496 & 1.526 & 2.547 & 219.000 & 0.012 \\
\hline $\mathrm{AH}$ & women & left & 1.524 & 1.268 & 2.494 & 219.000 & 0.013 \\
\hline O Mo f & women & left & 8.216 & 8.561 & -2.205 & 219.000 & 0.028 \\
\hline O Mo f - F Mo F & women & left & 0.534 & 0.302 & 3.366 & 219.000 & 0.001 \\
\hline O Mo f - F Mo F & women & right & 0.565 & 0.301 & 3.776 & 219.000 & 0.000 \\
\hline $\mathrm{CD} \alpha 1$ & men & left & 0.167 & 0.156 & 2.134 & 718.000 & 0.033 \\
\hline IIDA & men & left & 3.075 & 2.474 & 2.463 & 718.000 & 0.014 \\
\hline ADA & men & left & 1.724 & 1.532 & 3.308 & 718.000 & 0.001 \\
\hline $\mathrm{AH}$ & men & left & 1.518 & 1.403 & 1.972 & 718.000 & 0.049 \\
\hline O Mo f & men & left & 8.217 & 8.620 & -5.380 & 718.000 & 0.000 \\
\hline O Mo f - F Mo F & men & left & 0.486 & 0.277 & 3.846 & 718.000 & 0.000 \\
\hline ADA & men & right & 1.701 & 1.563 & 2.342 & 718.000 & 0.019 \\
\hline O Mo f & men & right & 8.386 & 8.635 & -3.061 & 718.000 & 0.002 \\
\hline O Mo f - F Mo F & men & right & 0.618 & 0.268 & 6.191 & 718.000 & 0.000 \\
\hline
\end{tabular}
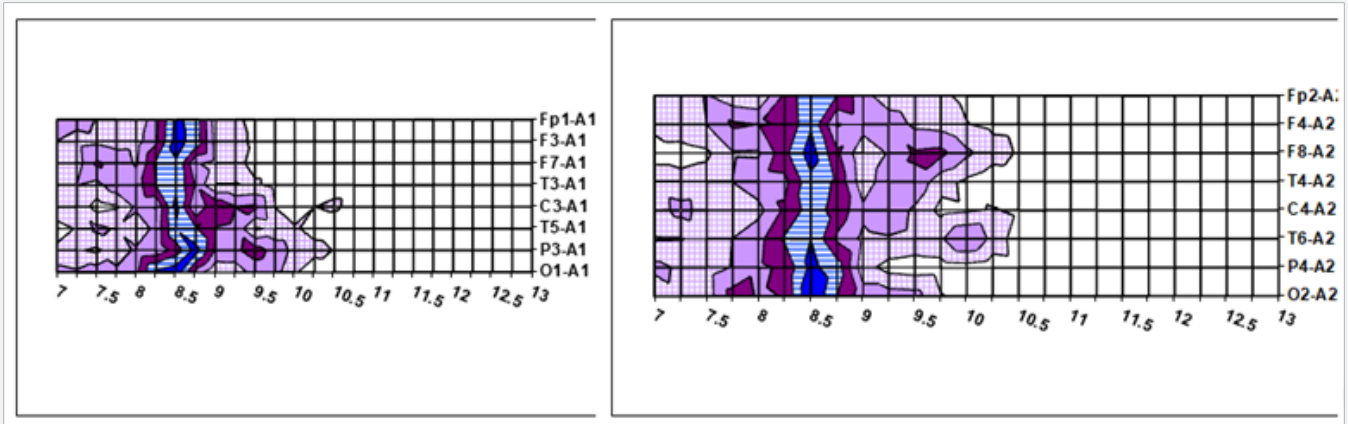

Figure 4: Average Dispersion Cartogram of Alpha Rhythm at DD, women.
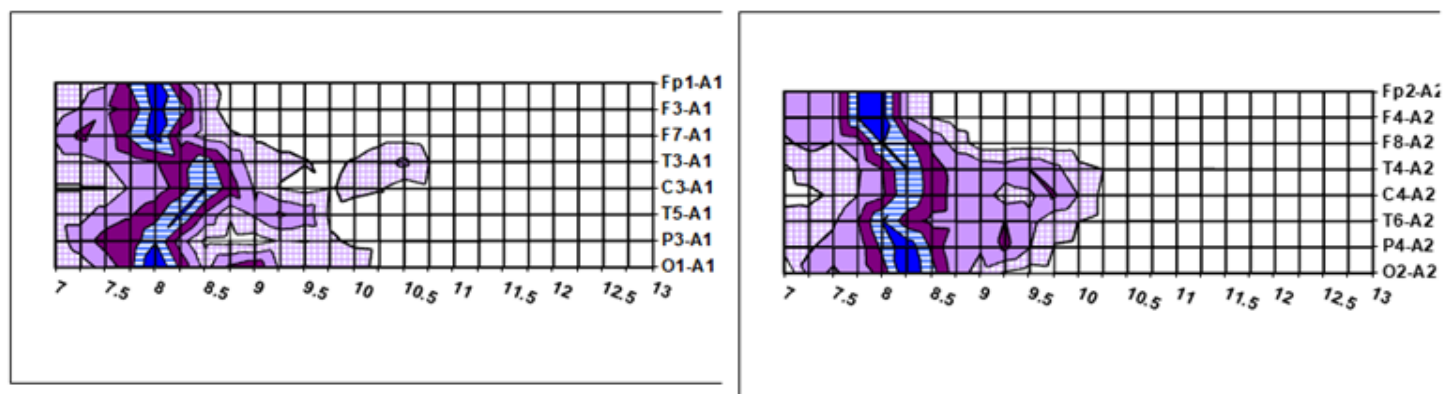

Figure 5: Average Dispersion Cartogram of Alpha Rhythm at the vascular dementia (VD), men.
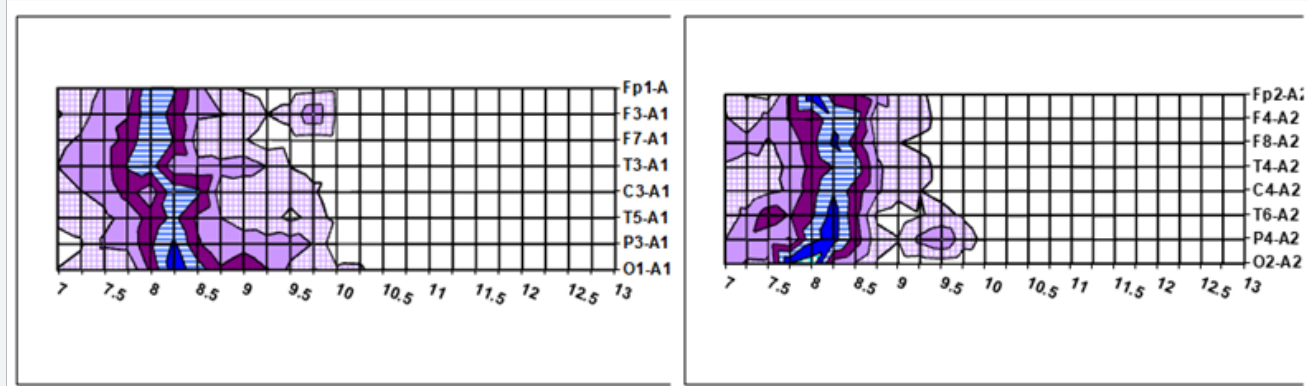

Figure 6: Average Dispersion Cartogram of Alpha Rhythm at VD, women. 

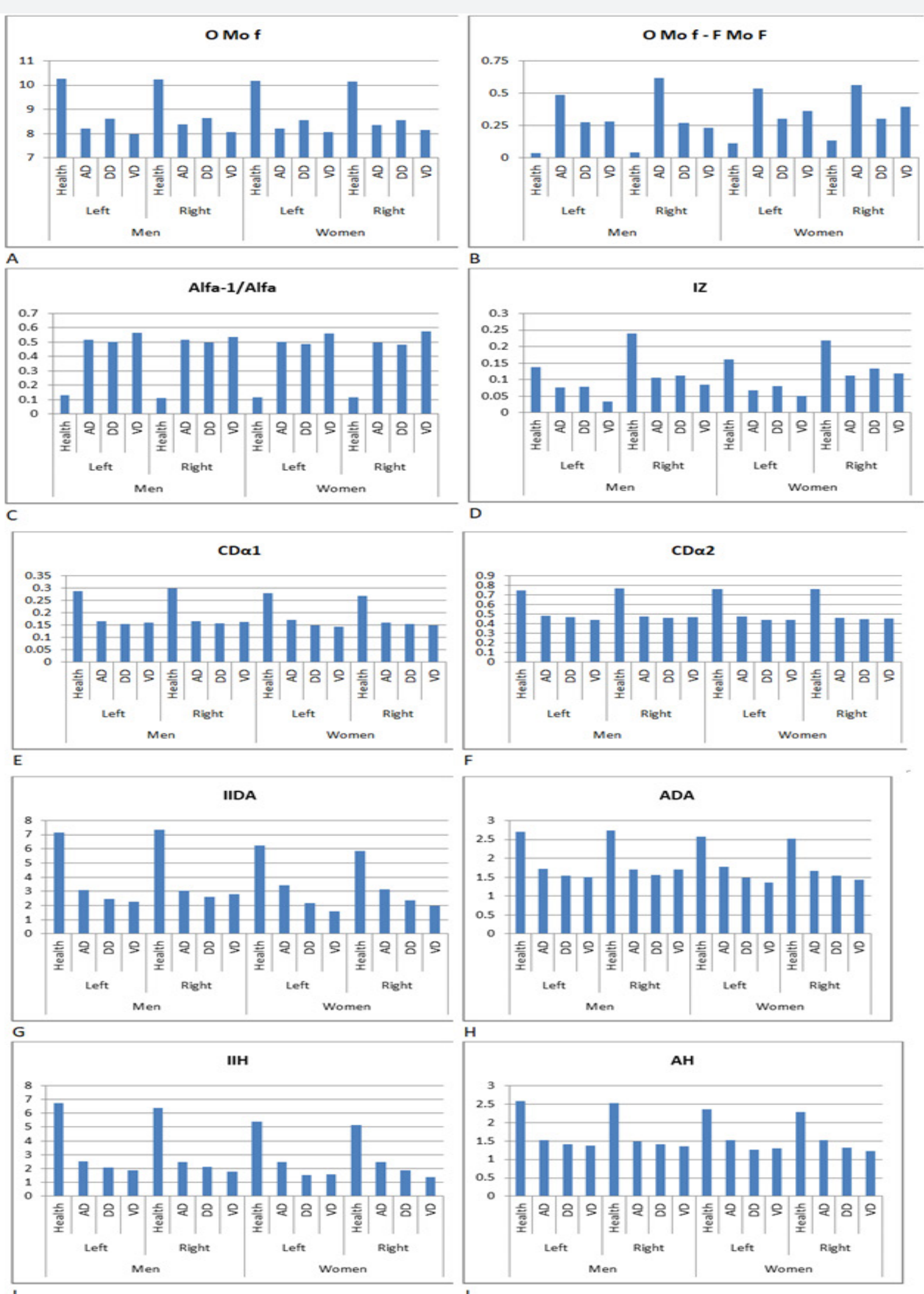

Figure 7: The comparative analysis of the DAFCAR indexes at different types of psychopathology with the help of histograms. 
Also violation of stratification of the schedule in the form of expansion of zones with low Kda1 values is observed that shows on increase in dispersion of this parameter around modal value, violation of a normality of distribution and increase of dispersion of an alpha rhythm. There is much an expressed interhemispheric asymmetry of cartograms that indicates the considerable share in a pathogenesis of diseases of exogenous factors - toxic, vascular and traumatic. Some increase in CD $\alpha 1$ value of Tables $2 \& 3$ in comparison with specified Figure 7 is bound to the fact that patients in these groups expressly were selected for leveling of their distinctions including on an age. Nevertheless obviously common decrease in values of indexes, in particular modal values of an alpha rhythm in each assignment.

Values of the DAFCAR indexes in the course of the research in comparison with other types of psychopathology which, according to us, are a consequence of an entropy of NGNB are presented in Tables $2 \& 3$. Of course, it is possible to estimate also digital values, but the graphic way is represented to us more visual. In the Figure 5 the same statistical data, but in the form of histograms are submitted. On them it is rather visually visible that the DAFCAR indexes gradually decrease in the sequence: AD - DD - VD.

\section{O Mo f}

Modal frequency of an alpha rhythm. The expressed delay of an alpha rhythm among AD - DD - VD is observed. Though their distinctions are insignificant, but statistically are significant (Table 4). Gender distinctions are insignificant. It is difficult to overestimate value of this index. Frequency of an alpha rhythm is very closely bound to cognitive processes, characterizing ability of a brain to assimilation of afferent information and its differentiations. In an ontogenesis normal the delayed alpha rhythm meets twice - at the beginning of process of neurophysiological maturing in the early childhood and during involution changes in an old age.

In both cases these processes have to be gradual, the uniform on both hemispheres and in various departments of a brain. And always they are followed by this or that degree of a cognitive failure and reflect natural dynamics of entropy of NGNB. In pathology the entropy of a brain accelerates and acceleration it can be no uniform, both interhemispheric, and interregional. Most brightly it is shown at schizophrenia at which there is the considerable delay of an alpha rhythm in frontal lobes in comparison with occipital. Though for a dementia the common delay of an alpha rhythm is the leader, but in case of AD moderately expressed hypofrontality phenomena having schizotypal character are observed what are probably connected also by features of clinic of AD.

\section{O Mo f - F Mo f}

A difference between modal frequencies in occipital and frontal leads. Value it is much more at a BP that demonstrates existence of a hypofrontality. At value DD and VD almost normal, considering that the value of a fiducial interval 0.01 0.06 has purely computing character - in reality the device can give values $0-0.25 \mathrm{~Hz}$, i.e. it is necessary to consider that values up to $0,25 \mathrm{~Hz}$ are normal.

\section{Alpha-1/Alpha}

A sluggish component of an alpha rhythm - it is sharply expressed, and it is one of distinctiveness of a dementia.

\section{IZ}

The index of zonality an indicator which unfairly is a little considered when studying an EEG probably owing to lack of its verification. In this research it was calculated by our characteristic unique technique. It sharply decreases in comparison with norm and is especially expressed at SD that is sign of sharp smoothing of zonal distinctions of an alpha rhythm. The negative IZ values - almost constant sign of a dementia.

\section{$\operatorname{CD} \alpha 1$ and $\operatorname{Cd} \alpha 2$}

The main indexes of dispersion change synchronously owing to the fact that one index are a derivate from another. Its values are considerably reduced in comparison with norm.

\section{IIDA}

The index reflecting an excess of a normal distribution of $\mathrm{CD} \alpha 1$, its flattening in graphics at decrease in an indicator. On a cartogram it is shown in the form of violation of stratification of the schedule, expansion of separate zones of representation of various frequencies of an alpha rhythm up to the total disappearance of these zones. Among psychopathology natural decrease of this index; at men of value is slightly higher, than at women.

\section{ADA}

Asymmetries of a normal distribution. Decreases among "Axis of dementia" that indicates increase in a zone of representation of a low - wave part of a range of an alpha rhythm; gender distinctions are insignificant.

\section{IIH, AH}

The indexes similar to IIDA and ADA, but in frontal assignments; key indicators of expressiveness of the functional hypofrontality. Undergo the same changes that IIDA and ADA, but values are lower than them, than in occipital leads. It is worth to remember that the phenomenon of a hypofrontality can be expressed in the following forms:

a) Monomodal shift of $\mathrm{O}$ Mo $\mathrm{f}$ in frontal assignments (increase in O Mo f value - F Mo f); at this IIH, AH can be almost normal - often happens at a schizophrenia debut

b) Simple dispersion changes in frontal assignments when indicators of $\mathrm{IIH}, \mathrm{AH}$ decrease, and $\mathrm{O}$ Mo f- F 
Mo $f$ value almost does not change - is often observed at a neurophysiological dismaturity and "slow" or treated schizophrenia. In this research we observe this phenomenon at DD and VD.

c) The mixed form - the expressed decrease of IIH, AH values at $(\mathrm{O}$ Mo $\mathrm{f}-\mathrm{F}$ Mo $\mathrm{f})>0.5$. Almost always points to changes in NGNB, the characteristic of diseases of a schizoid circle. In this research we observe this phenomenon at AD.

In Table 4 the statistical reliability of distinctions of mean values of indexes on a Student's test at various forms of psychopathology is presented. It is thought that there is no sense to compare a dementia to norm - values of indexes at the same time sharply differ. However differences between a BP and DD or BP and SD are very interesting. Data of this table confirm statistical reliability of changes which we found according to histograms in Figure 5. Changes which we observed when carrying out HVT (Figure 6) are not less interesting. The substantial increase of a share of endogenic reactions at all types of a dementia in comparison with norm is observed, at the same time the share of endogenic reactions at a $\mathrm{AD}$ is more, than at $\mathrm{DD}$ and $\mathrm{VD}$, reaching level, the characteristic of schizophrenia [14].

Thus, summing up our observations, one may say, that at a dementia of any genesis the following changes of DAFCAR are observed:

a) The considerable common delay of an alpha rhythm in all departments less than $8.5 \mathrm{~Hz}$

b) The considerable smoothing of zonal distinctions - decrease in a gradient "a nape - a forehead" up to the phenomenon of inversion of an alpha rhythm

c) The considerable increase of the common dispersion of an alpha rhythm, however in rare instances this sign is not expressed, especially at genetic forms of a dementia or

\section{purely involutional changes}

d) At an alcoholic dementia increase of a difference between modal values in occipital and frontal leads on "schizoid" type is often observed that can lead to a peculiar clinic of "paranoid changes on an organic hum noise" most often in the form of nonsense of jealousy, morbid depression and actions of violent character (Figure 7).

e) A high level of endogenic reactions at HVT at patients with a AD that allows to assume genetic predisposition them to the heavy course of alcoholism - to development of a dementia and tremens [8].

f) Results of researches of alcoholics with use of PET confirm the diffuse hypoperfusion which is especially expressed in frontal lobes [15-17]. These observations are very closely bound to our assumption that the main thing in a pathogenesis of alcoholic defeats is violation of rheological behavior of blood as a result of a denaturation of proteins under the influence of alcohol therefore perfusion of a brain decreases. Finally, as a result of a chronic hypoperfusion of a brain at alcoholism, it leads to degenerative processes in NGNB.

The revealed violations demonstrate disorganization of NGNB that can be caused by violation of functioning of a dorsal - lateral prefrontal associative circle which begins in convex department of frontal bark of a before pre-motive area, but also receives an afferentation from other associative zones of a cerebral cortex [15]. These departments are projected on a dorsal-lateral part of a head of a core having a tail which is bound to dorsal-medial departments of an external segment of a pale sphere and rostral department of a reticular part of black substance. From the last the impulsation goes to ventral forward and medal-dorsal cores of a thalamus and comes back to dorsal-lateral prefrontal cortex [18].

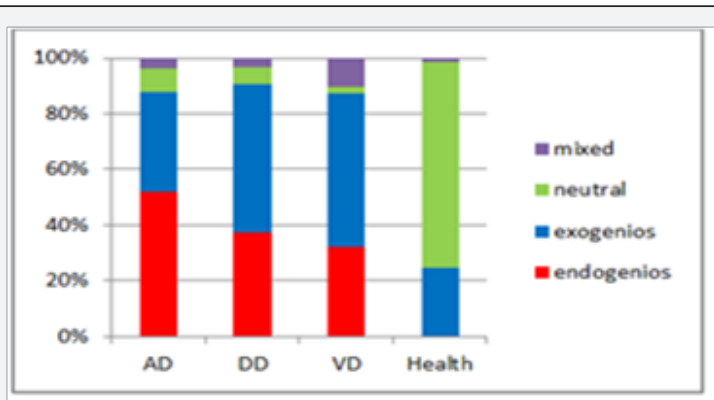

A

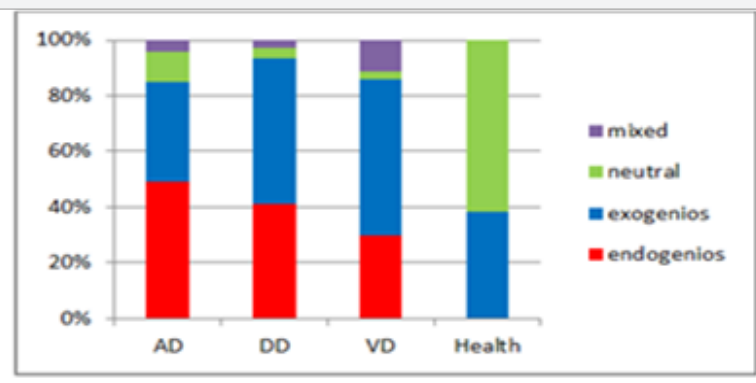

B

Figure 8: Distribution of results of HVT on reaction types at different types of psychopathology. A - men, B - women

All this most difficult complex of neurophysiological violations also makes a basis of the functional hypofrontality about which we repeatedly spoke in all previous articles of a cycle. It is also worth adding that according to F. Crews [19] there is a genetic predisposition to emergence of similar cognitive frustration. In return we want to add that the similar predisposition, most likely, is caused by some features of the biopower organization of activity of the neurons contributing to their low tolerance to deficiency of nutrients in the conditions of the increased functionality, for example, 


\section{Global Journal of Addiction \& Rehabilitation Medicine}

at a stress. These observations are confirmed by data of HVT (Figure 8).

It is apparent that the alcoholic dementia develops by the same rules, as all other types of a dementia - their basis is the total depression of function of NGNB which is shown sharp delay of an alpha rhythm in all departments of NGNB. However, at there is one feature - the expressed hypofrontality which is characteristic of all processes of a schizoid circle. And here appropriate to remember one psychological feature of topers bent to a paranoid and deviant behavior, the bound to violent acts. It well is explained by a hypofrontality which interferes with formation at the person of social and acceptable behavior models [7].

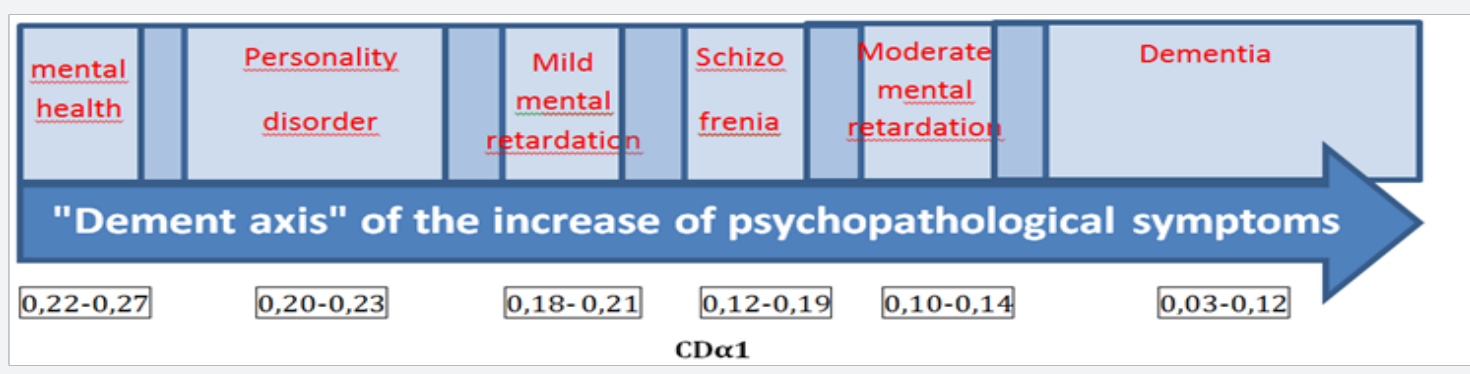

Figure 9: "Axis of Dementia" of the matching indexes, DAFCAR and distribution of some of the major forms of mental illness.

All this rather well explains some features of mentality of a toper. Most of all what, despite rather wide spread occurance of alcohol and, often, a large alcoholization, an alcoholism is not total confuses and the alcoholic dementia is not the fatal fate of all drinking population that cannot be told, for example, about drug addiction (Figure 9). Similar drug trafficking would become absolutely pernicious for mankind. Most likely, we deal with some genetic predisposition of separate individuals to a hypersensibility to pathophysiological influence of alcohol. And, this feature pathogenetically is intimately bound to diseases of a schizoid circle and deviant behavior (violent crime, tendency to a professional burning out, pedophilia etc) $[7,8,10,13]$.

The functional hypofrontality resulting from disorganization of activity of NGNB in frontal lobes therefore at assimilation of afferent information (process of internalization of information) there is a pathological polysemantic is the cornerstone of all these processes. In other words, the hypo function of frontal lobes leads to formation of inaccurate ideas of properties of the real surrounding in us therefore behavior patterns, unacceptable for society, are developed. In practice we have the patient who, at best, shows shallow strangenesses of behavior, and in the inferior - attacks on people around, suffers jealousy and morbid depression or falls into a delirium [20].

All these manifestations are rather just diagnosed by means of the DAFCAR method. Of course, this method is not comprehensive and exhaustive. Its main shortcoming is that it reflects "in the plane" properties of volume fractal process which happens in NGNB [6]. It is possible to eliminate this defect only introduction of noninvasive placement of microelectrodes in a brain. But this business not of it of the far future. Other shortcoming is that, studying oscillating motion, the DAFCAR method covers only its amplitude - frequenciest properties, passing phase. Undoubtedly, association DAFCAR with a coherence will yield still larger fruits, but it is destiny of more extensive researches (Figure 9).

Nevertheless, is more narrow at this stage of the development, the DAFCAR method allows to study at early stages mental diseases in dynamics of their development and treatment. Its application in screening researches, for example, by means of the DNPD device [7], will allow revealing at early stages patients for a further dispensary observation and restriction of penetration of mentally sick people into «protect» zones of society. This research will allow to turn, at last, psychiatry from speculative science in original, based on the dimensional the principles of evidential medicine. Perhaps, it is also a basis of its new paradigm. Summarizing everything, told in articles of a cycle [7-14] and in this article, it is possible to offer the following definition of a mental disease:

\section{Mental disease}

Inability of the patient to creation of social and acceptable models of the behavior and cognitive activity owing to formation of the pathological polysemantic, caused by violation of process of internalization of afferent information, which cornerstone the accelerated entropy of neuron - glial network of brain. Marker of this entropy is DAFCAR by means of which it is possible to measure degree of its expressiveness and topical parameters of distribution.

\section{Conclusion}

Feature of an alcoholic dementia is the accelerated entropy of NGNB with preferred damage of frontal lobes. There is a high probability of predisposition to development of a hypofrontality which is implemented by turning on of pathophysiological mechanisms of toxic influence of alcohol among which the leader is the expressed brain hypoperfusion, first of all in frontal lobes. Neuropsychological features of 
the person and cognitive violations at an alcoholic dementia rather fully are explained by the accelerated entropy of NGNB by means of the DAFCAR method which reveals the expressed delay of an alpha rhythm and increase of its dispersion, especially in frontal lobes. The DAFCAR method allows revealing at early stages predisposition investigated to alcoholism and other mental deviations. The DAFCAR method opens padding opportunities in search of a new paradigm of psychiatry on a dimensional basis.

\section{References}

1. Donaghy M (1993) Toxic and environmental disorders of the nervous system: Brain's Diseases of the Nervous System. $10^{\text {th }}$ edn / Ed. by J Wallon - Oxford etc. Oxford University Press, USA, pp. 513-529.

2. Kunze K (2002) Metabolic Encephalopathies. J Neurol 249(9): 11501159.

3. Harper C, Corbett D (1997) Alcoholism and dementia: The neuropathology of dementia / Ed. by MM Esiri, JH Morris, Cambridge: Cambridge University press, UK pp. 141-154.

4. Mclnlosh C, Chick J (2004) Alcohol and the nervous system. J Neurol Neurosurg Psychiatry 75 (Suppl 3): p. 16-21.

5. Renner JA, Morris JC (1994) Alcohol-associated dementia: Handbook of Dementing Illnesses / Ed. by JC Morris, Marcel Dekker publishing, New York, USA pp. 393-412.

6. Rosman S (2017) The Theoretical Foundations of Dispersion of Amplitude-Frequency Characteristics of the Alpha Rhythm of the EEG. Glob J Add \& Rehab Med 2(3): 1-8.

7. Rosman S, Kurakhina O (2017) Violent Crime in the Context of Entropy Neuron-Glial Networks of the Brain. Glob J Add \& Rehab Med 2(5): $1-10$.

8. Rosman S (2017) The Use of Analysis of Variance of the Alpha Rhythm of the EEG in the Study of the Pathogenesis of Alcoholism and the Causes of Alcoholic Deliria. Glob J Add \& Rehab Med 2(1): 1-8.

9. Rosman S (2017) To The Question about the Etiology of Mental Illness. Glob J Add \& Rehab Med 4(1): 1-3.

10. Rosman SV (2017) Borderline Personality Disorder in the Context of Entropy Neuron-Glial Networks of the Brain. Glob J Add \& Rehab Med 2(4): $1-6$.

11. Rosman SV, Filonov SM (2017) Cognitive Impairment in Oncology Practice in the Context of Entropy Neuron-glial Network of the Brane. Glob J Add \& Rehab Med 2(4).

12. Rosman SV (2017) Burnout Syndrome in the Context of Entropy Neuron-Glial Networks of the Brain. Glob J Add \& Rehab Med 3(3): 1-8.

13. Rosman SV (2017) Pedophilia in the Context of Entropy Neuron Glial Networks of the Brain. Glob J Add \& Rehab Med 4(2): 1-10.

14. Rosman SV (2017) The Debut of Schizophrenia in the Context of Entropy Neuron-Glial Network of the Brain. Glob J Add \& Rehab Med 3(4): 1-11.

15. Cummings JL (1993) Frontal-subcortical circuits and human behavior. Arch Neurol 50(8): 873-880.

16. Erbas B, Bekdik C, Erbengy G, Enünlü T, Aytac S, et al. (1992) Regional cerebral blood flow changes in chronic alcoholism using Tc-99m HMPAO SPECT: Comparison with CT parameters. Clinical Nuclear Medicine 17(2): 123-127.

17. Gilman S, Adams K, Koeppe R (1990) Cerebellar and frontal hypometabolism in alcoholic cerebellar degeneration studied with positron emission tomography. Ann Neurol 28(6): 775-785.

18. Mendelevich SV, Damulin IV, Sivolap Ju P (2010) Peculiarities of cognitive disorders in patients with neurological symptoms of chronic alcohol abuse. Mental Health 1: 52-57.

19. Crews FT, Nixon K (2009) Mechanisms of neurodegeneration and regeneration in alcoholism. Alcohol and Alcoholism 44(2): 115-127.

20. Dao Caslellana MH, Samson Y, Legault F, Martinot JL, Aubin HJ, et al. (1998) Frontal dysfunction in neurologically normal chronic alcoholic subjects: metabolic and neuropsychological findings. Psycholog Med 28(5): 1039-1048.

\section{Your next submission with Juniper Publishers}

will reach you the below assets

- Quality Editorial service

- Swift Peer Review

- Reprints availability

- E-prints Service

- Manuscript Podcast for convenient understanding

- Global attainment for your research

- Manuscript accessibility in different formats

( Pdf, E-pub, Full Text, Audio)

- Unceasing customer service

Track the below URL for one-step submission https://juniperpublishers.com/online-submission.php 